\title{
Synthesis and Characterization of Polyacrylonitrile Copolymers Containing Amine Groups
}

\author{
Yang Chengran \\ State Key Laboratory for Modification of Chemical \\ Fibers and Polymer Materials \\ Donghua University \\ Shanghai, China \\ e-mail: cryang230@mail.dhu.edu.cn
}

\author{
Zhang Yumei \\ State Key Laboratory for Modification of Chemical \\ Fibers and Polymer Materials \\ Donghua University \\ Shanghai, China \\ e-mail: zhangym@dhu.edu.cn
}

\author{
Wang Biao \\ State Key Laboratory for Modification of Chemical \\ Fibers and Polymer Materials \\ Donghua University \\ Shanghai, China \\ e-mail: wbiao2000@dhu.edu.cn
}

\begin{abstract}
Polyacrylonitrile copolymers containing amine groups (Poly(AN-VA-DEMA) copolymers) were synthesized by the aqueous precipitation copolymerization of acrylonitrile (AN), vinyl acetate (VA) and methacrylic acid 2-dimethylaminoethyl ester (DEMA) with a $\mathrm{Na}_{2} \mathrm{~S}_{2} \mathrm{O}_{5}-\mathrm{NaClO}_{3}$ redox initiating system. The influences of monomer concentration, temperature, $\mathrm{pH}$ value of the medium, initiator concentration and additive amount of DEMA on the yield and viscosity-average molecular weight $\left(M_{\eta}\right)$ of the Poly(AN-VA-DEMA) copolymer were systemically investigated. The composition of Poly(AN-VA-DEMA) copolymer were characterized by FTIR and NMR.
\end{abstract}

Keywords- polyacrylonitrile; methacrylic acid 2dimethylaminoethyl ester; amine groups; aqueous precipitation copolymerization; polymerization parameters

\section{INTRODUCTION}

Polyacrylonitrile (PAN) fiber is one of the major synthetic fibers which has been widely used in apparel, home furnishings and industrial fabrics because of its outstanding physical and chemical properties [1]. In order to endow PAN fiber with different functions like hydrophilicity, dyeability, antibacterial property, and flame-retardency many efforts have been made to modify PAN fibers by various methods, including copolymerization of functional monomers [2-6].

In recent years, much work has been carried out on methacrylic acid 2-dimethylaminoethyl ester (DEMA) [7]. The homopolymer of DEMA is a weak cationic polyelectrolyte in aqueous solutions, exhibiting high $\mathrm{pH}$ and thermal sensitivity which has applied as hydrogel, brush and nanofiltration membranes [8]. There also have been many studies on functional materials based on acrylonitrile and DEMA copolymer which has large potential applications on $\mathrm{CO}_{2}$ and dye adsorption, ion exchange, ultrafiltration and pH-responsive materials [911]. However, DEMA contains basic tertiary amine groups which has great influence on the polymerization process of PAN and the properties of end products. Previous reports hadn't paid much attention on the synthesis process of this copolymers. In this paper, Poly(AN-VA-DEMA) copolymer was synthesized by the aqueous precipitation copolymerization. The influences of polymerization parameters were investigated. The composition of the copolymer were characterized. parentheses, following the example.

\section{EXPERIMENTAL}

\section{A. Materials}

Acrylonitrile (AN) was purchased from China Petroleum \& Chemical Corporation (Shanghai, China), and was distilled before use. Vinyl acetate (VA), sodium pyrosulfite $\left(\mathrm{Na}_{2} \mathrm{~S}_{2} \mathrm{O}_{5}\right)$, sodium chlorate $\left(\mathrm{NaClO}_{3}\right)$ and 2mercaptoethanol were of analytical grade and purchased from Sinopharm Chemical Reagent (Shanghai, China). Methacrylic acid 2-dimethylaminoethyl ester was purchased from Xinyu Chemical Co., Ltd. (Jiangsu, China).

\section{B. Synthesis of the Poly(AN-VA-DEMA) Copolymer}

In the typical experiment, required amounts of $\mathrm{AN}$, VA, DEMA, $\mathrm{Na}_{2} \mathrm{~S}_{2} \mathrm{O}_{5}, \mathrm{NaClO}_{3}$ and deionized water were placed in a flask with nitrogen atmosphere. The reaction mixture was stirred continuously at $60^{\circ} \mathrm{C}$ for $1 \mathrm{~h}$, then terminated by $5 \mathrm{wt} \% \mathrm{NaOH}$ aqueous. The resultant mixture was washed thoroughly and filtered several times, dried at $60^{\circ} \mathrm{C}$ in vacuum for $12 \mathrm{~h}$ and then weighed. The viscosity-average molecular weight of various samples in 
$\mathrm{DMF}$ at $25^{\circ} \mathrm{C}$ were determined via a dilution method with an Ubbelohde viscometer [12].

\section{Characterization}

The FTIR spectra were recorded on a Nicolet 6700 FTIR spectrophotometer. ${ }^{1} \mathrm{H}-\mathrm{NMR}$ spectra were recorded on a Bruker av400 NMR spectrometer and DMSO-d6 was used as solvents.

\section{RESULTS AND DisCUSSION}

\section{A. Synthesis of the Poly(AN-VA-DEMA) Copolymer}

Poly(AN-VA-DEMA) copolymer was synthesized by the aqueous precipitation copolymerization of $\mathrm{AN}, \mathrm{VA}$ and DEMA with a $\mathrm{Na}_{2} \mathrm{~S}_{2} \mathrm{O}_{5}-\mathrm{NaClO}_{3}$ redox initiating system. The influences of monomer concentration, temperature, $\mathrm{pH}$ value of the medium, initiator concentration and additive amount of DEMA on the yield and $\mathrm{M}_{\eta}$ of the Poly(AN-VA-DEMA) copolymer were investigated to obtain optimum reaction conditions.

TABLE I. EFFECT OF MONOMER CONCENTRATION ON THE AQUEOUS PRECIPITATION COPOLYMERIZATION OF AN, VA AND DEMA

\begin{tabular}{|c|c|c|}
\hline $\begin{array}{c}\text { Monomer concentration } \\
(\boldsymbol{\%})\end{array}$ & $\mathbf{M}_{\boldsymbol{\eta}}\left(\mathbf{1 0}^{\mathbf{4}}\right)$ & Yield (\%) \\
\hline 15 & 7.82 & 70.9 \\
\hline 20 & 6.76 & 82.5 \\
\hline 25 & 6.15 & 85.1 \\
\hline 28 & 5.98 & 84.8 \\
\hline Other reaction conditions: temperature $=60{ }^{\circ} \mathrm{C}, \mathrm{pH}=2.0, \quad$ initiator concentration $=0.6 \%$,
\end{tabular}

$\mathrm{NaClO}_{3} / \mathrm{NaS}_{2} \mathrm{O}_{5(\text { mol) }}=1 / 3$, chain transfer concentration $=0.3 \%$, DEMA addition $=2.5 \%$

The yield and $\mathrm{M}_{\eta}$ of the copolymers prepared with different monomer concentration were shown in Table 1. As the monomer concentration increased, the yield increased, and $M_{\eta}$ of the copolymer decreased. The initiator concentration increased with monomer concentration, as the ratio of initiator/monomer was fixed. But the solubility of the initiator is much more than monomer, these changes could be explained by the increase of the radical concentration in the reaction system.

TABLE II. EFFECT OF TEMPERATURE ON THE AQUEOUS PRECIPITATION COPOLYMERIZATION OF AN, VA AND DEMA

\begin{tabular}{|c|c|c|}
\hline $\begin{array}{c}\text { Reaction } \\
\text { Temperature } \\
\left({ }^{\mathbf{0}} \mathbf{C}\right)\end{array}$ & $\mathbf{M}_{\mathbf{\eta}}\left(\mathbf{1 0}^{\mathbf{4}}\right)$ & Yield (\%) \\
\hline 45 & 7.29 & 73.4 \\
\hline 50 & 6.85 & 75.8 \\
\hline 55 & 6.78 & 82 \\
\hline 60 & 6.76 & 82.5 \\
\hline 65 & 6.59 & 84.2 \\
\hline \multicolumn{2}{|c|}{} \\
\hline
\end{tabular}
Other reaction conditions: monomer concentration $=15 \%, \mathrm{pH}=2.0$, initiator concentration $=0.6 \%$,
$\mathrm{NaClO}_{3} / \mathrm{NaS}_{2} \mathrm{O}_{5}$ (mol) $=1 / 3$, chain transfer concentration $=0.3 \%$, DEMA addition $=2.5 \%$.

The yield and $M_{\eta}$ of the copolymers prepared at different temperature were shown in Table 2. As the reaction temperature increased, the yield increased, and $M_{\eta}$ of the copolymer decreased. The initiator decomposition rate and free radical concentration increased as the reaction temperature increased, resulted in the acceleration of reaction rate which caused the raise of the yield. Meanwhile, the rate of chain transfer and termination also increased which resulted in the decrease of $M_{\eta}$. As excessively high temperature cause a tendency to implode, to ensure polymerization process steady, $60 \mathrm{oC}$ was the proper temperature.

TABLE III. EFFECT OF THE PH VALUE OF REACTION MEDIUM ON THE AQUEOUS PRECIPITATION COPOLYMERIZATION OF AN, VA AND DEMA

\begin{tabular}{|c|c|c|}
\hline $\begin{array}{c}\text { pH value of } \\
\text { reaction } \\
\text { medium }\end{array}$ & $\mathbf{M}_{\boldsymbol{\eta}}\left(\mathbf{1 0}^{\mathbf{4}}\right)$ & Yield (\%) \\
\hline 1.5 & 6.35 & 74.5 \\
\hline 2 & 6.76 & 82.5 \\
\hline 3 & 6.88 & 80.8 \\
\hline 3.5 & 7.09 & 78.3 \\
\hline
\end{tabular}

Other reaction conditions: temperature $=60^{\circ} \mathrm{C}$, monomer concentration $=15 \%$, initiato concentration $=0.6 \%, \mathrm{NaClO}_{3} / \mathrm{NaS}_{2} \mathrm{O}_{5}(\mathrm{~mol})=1 / 3$, chain transfer concentration $=0.3 \%$, DEMA addition $=2.5 \%$.

The yield and $\mathrm{M}_{\eta}$ of the copolymers prepared at different $\mathrm{pH}$ values of reaction medium were shown in Table 3. As $\mathrm{pH}$ increased, $\mathrm{M}_{\eta}$ of the copolymer increased. The yield increased as $\mathrm{pH}$ decreased, but when $\mathrm{pH}$ decreased to 1 the yield was the minimum. The effect of $\mathrm{pH}$ is mainly related to the mechanism of redox initiating system. In the $\mathrm{Na}_{2} \mathrm{~S}_{2} \mathrm{O}_{5}-\mathrm{NaClO}_{3}$ initiating system, component which really generates free radical is $\mathrm{H}_{2} \mathrm{SO}_{3}$. The mechanism are as follows:

$$
\begin{aligned}
& \mathrm{ClO}_{3}^{-}+\mathrm{H}_{2} \mathrm{SO}_{3} \stackrel{k}{\longrightarrow} \mathrm{ClO}_{2}^{-}+\mathrm{HSO}_{3}^{\bullet-}+\mathrm{HO}^{\bullet} \\
& \mathrm{HSO}_{3}^{\bullet-}+\mathrm{HO}^{\bullet} \longrightarrow \mathrm{SO}_{4}^{2-}+2 \mathrm{H}^{+}
\end{aligned}
$$

TABLE IV. THE IONIZATION EQUILIBRIUM OF $\mathrm{H}_{2} \mathrm{SO}_{3}, \mathrm{HSO}_{3}$ - AND $\mathrm{SO}_{32}$ - UNDER DIFFERENT PH VALUE [13]

\begin{tabular}{|c|c|c|c|c|}
\hline pH value & $\mathbf{1}$ & $\mathbf{2}$ & $\mathbf{3}$ & $\mathbf{4}$ \\
\hline $\mathrm{SO}_{3}{ }^{2-}(\mathrm{mol} \%)$ & 0.0000074 & 0.00031 & 0.0047 & 0.047 \\
\hline $\begin{array}{c}\mathrm{HSO}_{3}{ }^{-} \\
\left(\mathrm{mol}^{\circ}\right)\end{array}$ & 0.15 & 0.63 & 0.94 & 0.95 \\
\hline $\begin{array}{c}\mathrm{H}_{2} \mathrm{SO}_{3} \\
(\mathrm{~mol} \%)\end{array}$ & 0.85 & 0.37 & 0.055 & 0.005 \\
\hline
\end{tabular}

As can be seen in Table 4, the ionization equilibrium concentration of $\mathrm{H}_{2} \mathrm{SO}_{3}$ decreased as $\mathrm{pH}$ increased which meant free radical concentration deceased. The effect of $\mathrm{pH}$ is also reflected in the electric potential of the polymerization system. Low $\mathrm{pH}$ which caused low potential between polymer particles which would make the system unsteady and result in the decrease of the yield and $\mathrm{M}_{\eta}$.

TABLE V. EFFECT OF THE INITIATOR CONCENTRATION ON THE AQUEOUS PRECIPITATION COPOLYMERIZATION OF AN, VA AND DEMA

\begin{tabular}{|c|c|c|}
\hline $\begin{array}{c}\text { Initiator } \\
\text { concentration } \\
(\boldsymbol{\%})\end{array}$ & $\mathbf{M}_{\boldsymbol{\eta}}\left(\mathbf{1 0}^{\mathbf{4}}\right)$ & Yield (\%) \\
\hline 0.3 & 7.58 & 78.7 \\
\hline 0.5 & 6.89 & 80.6 \\
\hline 0.6 & 6.76 & 82.5 \\
\hline 0.7 & 6.49 & 85.2 \\
\hline \multicolumn{2}{|c|}{ conditions: temperature $=60^{\circ} \mathrm{C}$, monomer concentration $=15 \%$, }
\end{tabular}

Other reaction conditions: temperature $=60^{\circ} \mathrm{C}$, monomer concentration $=15 \%, \quad \mathrm{pH}=2.0$, $\mathrm{NaClO}_{3} / \mathrm{NaS}_{2} \mathrm{O}_{5(\mathrm{~mol})}=1 / 3$, chain transfer concentration $=0.3 \%$, DEMA addition $=2.5 \%$.

The yield and $M_{\eta}$ of the copolymers prepared with different Initiator concentration were shown in Table 5. As initiator concentration increased, the yield increased and $\mathrm{M}_{\eta}$ decreased which were caused by the increase of free radical concentration. 
TABLE VI. EFFECT OF DEMA ON THE AQUEOUS PRECIPITATION COPOLYMERIZATION OF AN, VA AND DEMA

\begin{tabular}{|c|c|c|}
\hline $\begin{array}{c}\text { DEMA } \\
\text { addition }(\%)\end{array}$ & $M_{\eta}\left(10^{4}\right)$ & Yield (\%) \\
\hline 0.5 & 7.54 & 78.5 \\
\hline 1.0 & 7.12 & 81.2 \\
\hline 1.5 & 6.8 & 83 \\
\hline 2.0 & 6.72 & 83.2 \\
\hline 2.5 & 6.59 & 84.1 \\
\hline
\end{tabular}
addtion $=2.5 \%$.

The yield and $M_{\eta}$ of the copolymers prepared with different amount of DEMA were shown in Table 6. As DEMA addition increased, the yield increased and $M_{\eta}$ decreased. When DEMA addition was above $1.5 \%$, the yield and $M_{\eta}$ nearly remained unchanged. These were caused by the increase of system viscosity after addition of DEMA.

On the basis of the above results and the balance between yield and the spinnability, which was determined by the $\mathrm{M}_{\eta}$ of the copolymer, the optimum reaction conditions were as follows: temperature $=60^{\circ} \mathrm{C}$, monomer concentration $=15 \%, \mathrm{pH}=2.0$, initiator concentration $=0.6 \%$, $\mathrm{NaClO}_{3} / \mathrm{Na}_{2} \mathrm{~S}_{2} \mathrm{O}_{5} \quad$ (mol) $=1 / 3$, chain transfer concentration $=0.3 \%$ and DEMA addition $=2.5 \%$

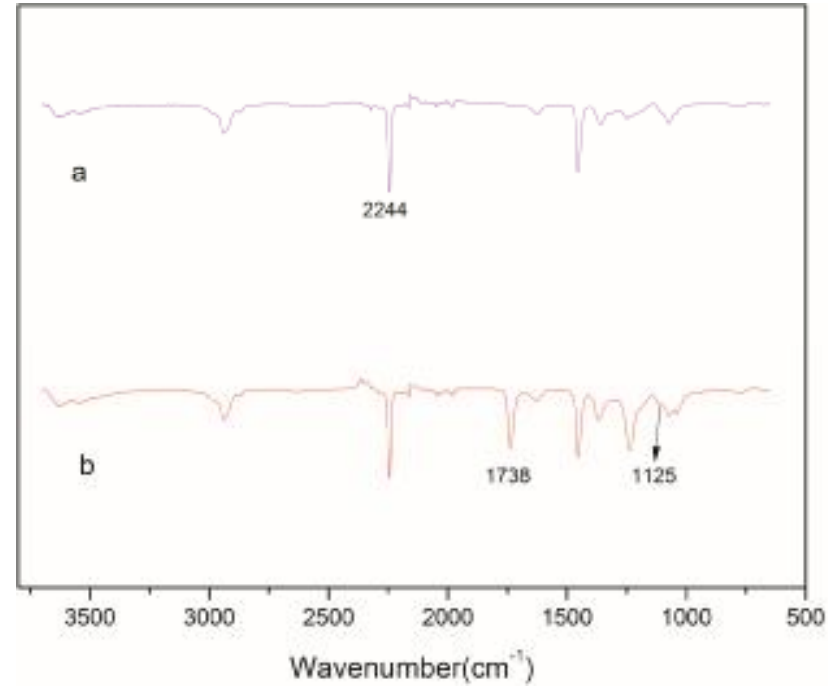

Figure 1. FTIR spectrum of (a) PAN and (b) Poly(AN-VA-DEMA)

Fig. 2 shows ${ }^{1} \mathrm{H}-\mathrm{NMR}$ spectrum of PAN homopolymer and Poly(AN-VA-DEMA). In Fig. 2, Peak 1 and Peak 4 are the peaks $\beta \mathrm{H}^{1}$ and $\alpha \mathrm{H}^{1}$ of in $\mathrm{AN}$ group. Peak 2 and Peak 3 are the peaks of $\mathrm{CH}_{3}$ bonded to amino and ester. It was noticed that Peak 5 and Peak 6 are weak and even level to the base line. Those are the peaks of $\mathrm{CH}_{2}$ bonded to ester groups in DEMA and VA. The ${ }^{1} \mathrm{H}-$
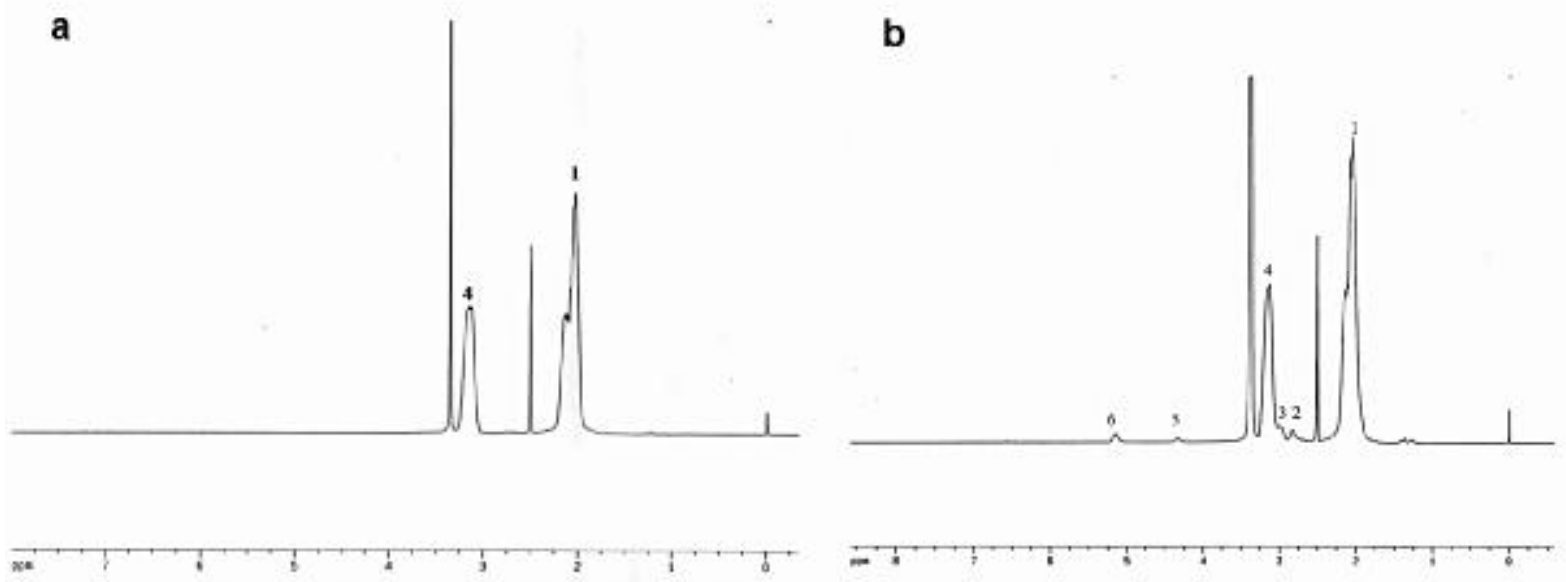

Figure 2. ${ }^{1}$ H-NMR spectrum of (a) PAN and (b) Poly(AN-VA-DEMA)

B. Characterization of Poly(AN-VA-DEMA) Copolymer

Fig. 1 shows the FTIR spectra of PAN homopolymer and Poly(AN-VA-DEMA). As demonstrated in Fig. 1, the typical absorption peaks of PAN homopolymer are as follows: stretching of $\mathrm{CH}_{2}$ at $2940 \mathrm{~cm}^{-1}$, stretching of $\mathrm{C} \equiv \mathrm{N}$ at $2240 \mathrm{~cm}^{-1}$, bending of $\mathrm{CH}_{2}$ at $1454 \mathrm{~cm}^{-1}$ and rocking of $\mathrm{CH}_{2}$ at $1366 \mathrm{~cm}^{-1}$. For Poly(AN-VA-DEMA), in addition to the characteristic peaks above, the spectrum exhibited a peak of $v C=O$ at $1738 \mathrm{~cm}^{-1}$ and an peak at $1125 \mathrm{~cm}^{-1}$ from C-N stretching of $-\mathrm{N}\left(\mathrm{CH}_{3}\right)_{2}$ groups. It is obvious that amine groups was successfully copolymerized on the polymer chain after the polymerization.
NMR spectrum confirmed that amine groups were existed in the polymer chain.

\section{CONCLUSIONS}

Various Poly(AN-VA-DEMA) copolymers containing amino groups were synthesized by the aqueous precipitation copolymerization of AN, VA and DEMA. The yield of copolymerization increased with the increase of monomer concentration, temperature, initiator concentration, DEMA addition and the decrease of $\mathrm{pH}$. The decrease of monomer concentration, temperature, initiator concentration and DEMA addition caused a 
increase in $\mathrm{M}_{\eta}$ of the copolymers. The optimum reaction conditions of the copolymerization were as follows: temperature $=60^{\circ} \mathrm{C}$, monomer concentration $=15 \%, \mathrm{pH}=2.0$, initiator concentration $=0.6 \%, \mathrm{NaClO}_{3} / \mathrm{Na}_{2} \mathrm{~S}_{2} \mathrm{O}_{5}$ (mol) $=1 / 3$, chain transfer concentration $=0.3 \%$ and DEMA addition $=2.5 \%$. The chemical composition were characterized by FTIR and NMR which indicated that amino groups were existed on the polymer chain.

\section{ACKNOWLEDGMENT}

This work is financially supported Shanghai Leading Academic Discipline Project (No. B603) and the Program of Introducing Talents of Discipline to Universities (No.111-2-04).

\section{REFERENCES}

[1] Lewin, M. \& Pearce, E.M., Handbook of Fiber Chemistry, Second Edition, Revised and Expanded, Taylor \& Francis, pp. 905-924, 1998 .

[2] Nie, F.Q., Xu, Z.K., Ming, Y.Q., Kou, R.Q., Liu, Z.M. \& Wang, S.Y., Preparation and characterization of polyacrylonitrile-based membranes: Effects of internal coagulant on poly(acrylonitrile-co-maleic acid) ultrafiltration hollow fiber membranes. Desalination, 160(1), pp. 43-50, 2004.

[3] Nie, F.-Q., Xu, Z.-K., Yang, Q., Wu, J. \& Wan, L.-S., Surface modification of poly(acrylonitrile-co-maleic acid) membranes by the immobilization of poly(ethylene glycol). Journal of Membrane Science, 235(1-2), pp. 147-155, 2004.

[4] Wang, M., Wu, L.-G., Mo, J.-X. \& Gao, C.-J., The preparation and characterization of novel charged polyacrylonitrile/PES-C blend membranes used for ultrafiltration. Journal of Membrane Science, 274(1-2), pp. 200-208, 2006.
[5] Groth, T., Seifert, B., Malsch, G., Albrecht, W., Paul, D. Kostadinova, A., Krasteva, N. \& Altankov, G., Interaction of human skin fibroblasts with moderate wettable polyacrylonitrile-copolymer membranes. Journal of Biomedical Materials Research, 61(2), pp. 290-300, 2002.

[6] Krasteva, N., Harms, U., Albrecht, W., Seifert, B., Hopp, M., Altankov, G. \& Groth, T., Membranes for biohybrid liver support systems - investigations on hepatocyte attachment, morphology and growth. Biomaterials, 23(12), pp. 2467-2478, 2002.

[7] Guice, K.B., Synthesis \& characterization of temperatureand $\mathrm{pH}$ - responsive nanostructures derived from block copolymers containing statistical copolymers of HEMA and DMAEMA, Ph.D. Thesis, The University of Texas at Austin, 2008.

[8] Su, Y. \& Li, C., Tunable water flux of a weak polyelectrolyte ultrafiltration membrane. Journal of Membrane Science, 305(1-2), pp. 271-278, 2007.

[9] Fujimoto, K., Kinugawa, H., Kitao, T., Kamiya, Y. \& Ogata, N., Specialty polymeric membranes. V. Selective permeation of carbon dioxide through synthetic polymeric membranes having 2-(N,N-dimethyl)aminoethoxycarbonyl moiety. Journal of Applied Polymer Science, 58(10), pp. 1771-1778, 1995.

[10] Muñoz-Bonilla, A. \& Fernández-García, M., Polymeric materials with antimicrobial activity. Progress in Polymer Science, 37(2), pp. 281-339, 2012.

[11] Linton, D., Driva, P., Sumpter, B., Ivanov, I., Geohegan, D., Feigerle, C. \& Dadmun, M.D., The importance of chain connectivity in the formation of non-covalent interactions between polymers and single-walled carbon nanotubes and its impact on dispersion. Soft Matter, 6(12), pp. 2801, 2010.

[12] Zhao, Z., Acrylic analysis and test, Textile Industry Press, Beijing, 1983

[13] Jiang, C., Novel polymerization process of polyacrylonitrile and Monte Carlo simulation for dispersed polymerization system, Master's thesis, Zhejiang University, 2001. 